\title{
Preparação e caracterização de catalisadores ácidos de zircônia sulfatada para aplicação na esterificação do óleo de algodão
}

\section{(Preparation and characterization of sulfated zirconia acid catalysts for application in the esterification of cottonseed oil)}

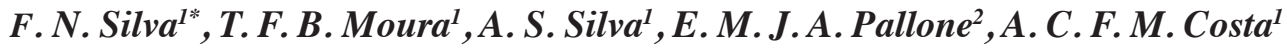 \\ ${ }^{1}$ Pós-graduação em Engenharia de Materiais, Universidade Federal de Campina Grande, \\ Av. Aprígio Veloso 882, Campina Grande, PB, Brasil 58109-970 \\ ${ }^{2}$ Departamento de Ciências Básicas, Universidade de S. Paulo, Pirassununga, SP, Brasil \\ *fnilson.s@hotmail.com
}

\begin{abstract}
Resumo
Esse trabalho objetivou produzir zircônia por síntese de combustão, analisar a estrutura e morfologia comparativamente com um $\mathrm{ZrO}_{2}$ monoclínico comercial e investigar a sulfatação, visando obter catalisadores ácidos para uso na esterificação do óleo de algodão para biodiesel. As amostras foram caracterizadas por difração de raios X, microscopia eletrônica de varredura (MEV), determinação de área de superfície específica pelo método de BET, espectroscopia no infravermelho (FTIR), análise térmica (TG/ DrTG/DTA), distribuição granulométrica, pH e cromatografia. A amostra sintetizada evidenciou a formação da fase majoritária monoclínica com traços da fase ortorrômbica, enquanto que a amostra comercial apresentou apenas a fase monoclínica. No processo de sulfatação, verificou-se o surgimento de traços da fase tetragonal, típico de zircônia sulfatada, com a permanência da fase majoritária monoclínica nas duas amostras. Com a impregnação do íon sulfato na superfície das amostras, foi possível observar um acréscimo no tamanho das partículas, conforme pôde ser observado nas caracterizações de BET, distribuição granulométrica e MEV, que também apontaram morfologia homogênea, constituída de partículas finas de formato aproximadamente esférico para ambas as amostras. A cromatografia indicou conversão de 65,5 e 91,8\% em ésteres metílicos para as amostras de $\mathrm{SO}_{4}^{2-} / \mathrm{ZrO}_{2}$ sintetizada e comercial, respectivamente. Os resultados indicaram que a sulfatação aumentou a acidez, o que foi comprovado pelo decréscimo do $\mathrm{pH}$ que variou de 5,12 a 2,65, o que contribuiu significativamente para o aumento da conversão, indicando que o $\mathrm{SO}_{4}{ }^{2-} / \mathrm{ZrO}_{2}$ é um catalisador promissor na esterificação.
\end{abstract}

Palavras-chave: zircônia sulfatada, $\mathrm{ZrO}_{2}$, reação de combustão, esterificação, biodiesel.

\begin{abstract}
This work aimed to produce zirconia by combustion synthesis, to analyze the structure and morphology comparatively with a commercial monoclinic $\mathrm{ZrO}_{2}$, as well as, to investigate the sulfation, aiming to obtain acid catalysts for its use in the esterification of cotton oil for biodiesel. The samples were characterized by X-ray diffraction, scanning electron microscopy (SEM), specific surface area by BET method, infrared spectroscopy (FTIR), thermal analysis (TG/DrTG/DTA), granulometric distribution, pH and chromatography. The synthesized sample evidenced the formation of the monoclinic phase with traces of the orthorhombic phase, while in the commercial sample only the monoclinic phase was observed. In the sulfation process, traces of the tetragonal phase, typical of sulfated zirconia, were observed with the presence of the monoclinic phase in the two samples. With the impregnation of the sulfate ion on the surface of the samples, an increase in the particle size was observed, as seen in the characterization of BET, granulometric distribution and SEM, which also indicated a homogeneous morphology consisting of fine particles of approximately spherical shape for both samples. The chromatography indicated conversion of 65.5 and $91.8 \%$ in methyl esters to the synthesized and commercial $\mathrm{SO}_{4}^{2-} / \mathrm{ZrO}_{2}$, respectively. The results indicated that the sulfation increased the acidity, which was evidenced by the decrease in the $\mathrm{pH}$, ranging from 5.12 to 2.65 , which contributed significantly to the increase of the conversion, indicating that the $\mathrm{SO}_{4}^{2-} / \mathrm{ZrO}_{2}$ is a promising catalyst in the esterification.

Keywords: sulfated zirconia, $\mathrm{ZrO}_{2}$, combustion reaction, esterification, biodiesel.
\end{abstract}

\section{INTRODUÇÃO}

A zircônia $\left(\mathrm{ZrO}_{2}\right)$ apresenta transformações polimórficas e sua estrutura cristalina pode sofrer alterações na medida em que variações ocorrem na temperatura, sem alteração da composição química. As mudanças cristalinas mais comuns são: monoclínica $(m)$, tetragonal (t) e cúbica [1-4], apesar de outra fase de transição, não majoritária, possa ocorrer durante o processo de síntese, denominada de ortorrômbica

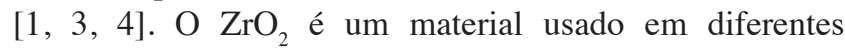
setores tecnológicos, como na engenharia, na medicina, na odontologia e na catálise, devido às suas propriedades 
mecânicas (elevada resistência à flexão, alta tenacidade à fratura, alto módulo de elasticidade e alta resistência ao desgaste), alta estabilidade química, biocompatibilidade e excelente aparência estética $[4,5]$, o que o torna um material bastante versátil em suas características e possibilita seu uso em várias aplicações tecnológicas, tais como revestimento refratário, material semicondutor [6], membranas [7], próteses e implantes dentários [8], implantes ortopédicos [9], materiais biológicos [10], pigmentos, dispositivos piezoeléctricos, sensores de oxigênio [11], suporte de catalisadores [12], assim como catalisador sulfatado para produção de biodiesel [13].

Estudo na literatura [14] relata que a zircônia é bem cotada na catálise devido à alta acidez, induzida por sulfatação, sendo utilizada em diferentes processos industriais, tais como: isomerização de hidrocarbonetos, acilação de Friedel-Crafts, aquilação e esterificação. Em produção de laboratório, vários métodos alternativos são utilizados para a obtenção da zircônia, podendo-se citar como os mais comuns: sol-gel [6], Pechini [15], coprecipitação [16] e reação de combustão [17]. A incorporação do ânion sulfato $\left(\mathrm{SO}_{4}{ }^{2-}\right)$ à zircônia, após o processo de sulfatação, permite o aumento da atividade catalítica deste material devido à formação de sítios catalíticos conhecidos como superácidos. A superacidez é atribuída à formação de vários sítios de Brönsted que são vizinhos a poderosos sítios ácidos de Lewis e ambos os sítios tendem a aumentar a acidez do catalizador. O sítio ácido de Lewis aparece devido ao efeito indutor exercido pelo ânion sulfato em relação ao íon metálico que fica deficiente de elétrons; já os sítios de Brönsted são formados pela presença de sulfato na amostra $[18,19]$. A zircônia sulfatada é um catalisador ácido forte, e outros catalisadores ácidos sólidos típicos, como as zeólitas, não apresentam atividade equivalente. Um dos fatores que controla a atividade catalítica da zircônia sulfatada é a quantidade de íons sulfatos em sua superfície [18].

Diante desse contexto, a relevância do presente trabalho foi desenvolver um catalisador superácido a partir da sulfatação de zircônias, uma sintetizada por reação de combustão e outra zircônia comercial, avaliando o desempenho desses compostos como catalisadores nas reações de esterificações etílicas do óleo de algodão, visando a produção de um combustível mais limpo e puro. Além disso, objetivou-se realizar uma análise comparativa entre as características morfológicas e estruturais de ambas as zircônias.

\section{MATERIAIS E MÉTODOS}

Foram utilizados dois tipos de $\mathrm{ZrO}_{2}$ : i) zircônia sintetizada por reação de combustão por produção em bateladas de $15 \mathrm{~g}$ por reação; e ii) zircônia comercial fornecida pela empresa Saint-Gobain Zirpro ( $\mathrm{ZrO}_{2}$ comercial). Para a obtenção do $\mathrm{ZrO}_{2}$ por reação de combustão, a sulfatação das amostras de $\mathrm{ZrO}_{2}$ e posteriormente a realização de teste catalítico por reação de esterificação, foram utilizados os reagentes descritos na Tabela I.

$\mathrm{Na}$ síntese por reação de combustão do $\mathrm{ZrO}_{2}$, a composição estequiométrica da mistura inicial foi calculada com base nas valências dos elementos reativos, de acordo com a química dos propelentes e explosivos para estequiometria, considerando a relação reagente oxidantes/redutor equivalente à unidade; as quantidades estequiométricas dos reagentes para síntese corresponderam: 1 mol de n-propóxido de zircônio e 12 moles de ureia [20]. Foram utilizados $6,19 \mathrm{~mL}$ de n-propóxido de zircônio e $14,41 \mathrm{~g}$ de ureia para produzir o $\mathrm{ZrO}_{2}$ sintetizado. Para essa quantidade de reagentes foram produzidos $3,45 \mathrm{~g}$ de produto por batelada. A fonte de aquecimento externo usada foi uma base cerâmica com resistência em espiral (temperatura média máxima de $687^{\circ} \mathrm{C}$ ), e um recipiente de aço inoxidável com capacidade de produção de $15 \mathrm{~g}$ do produto [4].

A zircônia obtida por reação de combustão e a zircônia comercial foram desaglomeradas com auxílio de almofariz e peneiradas em peneira 325 mesh $(44 \mu \mathrm{m})$ e posteriormente foram sulfatadas. A sulfatação foi realizada conforme modificação na metodologia proposta em [21]. A modificação aconteceu devido à redução do tempo de calcinação da amostra e na adição de água ao meio. $\mathrm{O}$ procedimento consistiu na secagem do $\mathrm{ZrO}_{2}$ em estufa sem circulação de ar a $110{ }^{\circ} \mathrm{C}$ por $24 \mathrm{~h}$. Transcorrido esse período, realizouse a mistura do $\mathrm{ZrO}_{2}$ com o sulfato de amônia, $\left(\mathrm{NH}_{4}\right)_{2} \mathrm{SO}_{4}$, de modo a proporcionar um teor de íon $\mathrm{SO}_{4}{ }^{2-}$ de $30 \%$ em relação à massa do $\mathrm{ZrO}_{2}$. A mistura foi conduzida em almofariz por cerca de $20 \mathrm{~min}$, sendo que ao sistema foram adicionados $0,20 \mathrm{~mL}$ de água deionizada. Ao término desse procedimento, a mistura foi seca em estufa a $70{ }^{\circ} \mathrm{C}$ para posteriormente ser calcinada em forno mufla a $600{ }^{\circ} \mathrm{C}$ por 3 $\mathrm{h}$, sendo a taxa de aquecimento de $5{ }^{\circ} \mathrm{C} / \mathrm{min}$.

As fases presentes, o grau de cristalização e o tamanho de cristalito das amostras foram determinados utilizando um difratômetro de raios X Shimadzu (XRD 6000, radiação

Tabela I - Reagentes utilizados no procedimento experimental.

[Table I - Reagents used in the experimental procedure.]

\begin{tabular}{cccc}
\hline Reagente & Fórmula molecular & Massa molecular $(\mathrm{g} / \mathrm{mol})$ & Pureza (\%) \\
\hline n-propóxido de zircônia & $\mathrm{Zr}\left(\mathrm{OCH}_{2} \mathrm{CH}_{2} \mathrm{CH}_{3}\right)_{4}$ & 327,57 & 70 \\
Ureia & $\mathrm{CO}\left(\mathrm{NH}_{2}\right)_{2}$ & 60,06 & 89 \\
Etanol (álcool etílico) & $\mathrm{C}_{2} \mathrm{H}_{5} \mathrm{OH}$ & 46,07 & 95,5 \\
Ácido oleico & $\mathrm{C}_{18} \mathrm{H}_{34} \mathrm{O}_{2}$ & 282,47 & $85-95$ \\
Sulfato de amônio & $\left(\mathrm{NH}_{4}\right)_{2} \mathrm{SO}_{4}$ & 132,14 & 99 \\
\hline
\end{tabular}


$\mathrm{CuK} \alpha$ ). O tamanho médio de cristalito foi calculado a partir da linha de alargamento de raios $\mathrm{X}\left(\mathrm{d}_{111}\right)$ por meio da deconvolução da linha de difração secundária do cério policristalino (utilizado como padrão), utilizando-se a equação de Scherrer [22]. A cristalinidade foi determinada a partir da razão entre a área integrada do pico referente à fase cristalina e a área referente à fração amorfa, usando o software da Shimadzu. Para identificação das fases, o programa Pmgr (Shimadzu) foi utilizado e o banco de dados JCPDF foi acessado. Os aspectos morfológicos das amostras foram analisados por meio de microscopia eletrônica de varredura (MEV, Philips, Megellan 400 L). A determinação da área superficial específica das amostras foi realizada pelo método de adsorção de nitrogênio desenvolvido por Brunauer, Emmett e Teller (BET). A partir de isotermas de adsorção de gases foi possível obter as características de suas texturas, sendo utilizado um equipamento ASAP 2420, Micromeritics. Essa técnica também foi usada para determinar o tamanho médio de aglomerados de partículas (diâmetro esférico equivalente) por meio da seguinte equação [23]:

$$
\mathrm{D}_{\mathrm{BET}}=\frac{6}{\mathrm{~S}_{\mathrm{BET}} \cdot \rho}
$$

onde, $\mathrm{D}_{\mathrm{BET}}$ é o diâmetro médio equivalente $(\mathrm{nm}), \mathrm{S}_{\mathrm{BET}}$ é área superficial determinada pelo método BET $\left(\mathrm{m}^{2} / \mathrm{g}\right)$, Q é densidade teórica $\left(\mathrm{g} / \mathrm{cm}^{3}\right)$ e 6 é um fator calculado experimentalmente em [23] e adotado para partículas de formato consideradas esféricas e sem rugosidade. A densidade teórica (@) utilizada foi de $5,606 \mathrm{~g} / \mathrm{cm}^{3}$ para a zircônia monoclínica, obtida de acordo com o arquivo cristalográfico JCPDS 65-2357. O volume de poro e o diâmetro de poro foram calculados pela teoria desenvolvida por Brunauer, Joyner e Helenda (BJH). Os espectros de infravermelho por transformada de Fourier (FTIR) das composições foram coletados em pastilhas de $\mathrm{KBr}$ a $1 \%$, usando um espectrômetro Spectrum BX, Perkin Elmer, em número de onda entre 4000 e $500 \mathrm{~cm}^{-1}$, com resolução de $4 \mathrm{~cm}^{-1}$ e 20 varreduras. A espectroscopia de infravermelho foi utilizada para atestar a identidade dos compostos, dando informações estruturais sobre as bandas dos agrupamentos da molécula.

As análises termogravimétricas (TG/DrTG/DTA) das amostras foram realizadas em um equipamento da Shimadzu, DTG 60H. A análise foi realizada utilizando $5 \pm 0,5 \mathrm{mg}$ de amostra, sendo acondicionados em um suporte de alumina com taxa de aquecimento de $12,5^{\circ} \mathrm{C} \cdot \mathrm{min}^{-1}$, na faixa de temperatura variando da ambiente até $1000{ }^{\circ} \mathrm{C}$, sob atmosfera dinâmica de nitrogênio, com vazão de 50
$\mathrm{mL} \cdot \mathrm{min}^{-1}$, buscando identificar a temperatura de eliminação da parte orgânica das amostras, dos formadores de poros e as possíveis transformações de fase em temperaturas elevadas. Com a finalidade de determinar a distribuição do tamanho de partículas das amostras, foi utilizada a técnica de difração a laser. O equipamento utilizado foi o analisador de nanopartículas SZ-100 (Horiba), que mediu a granulometria na faixa de $0,3 \mathrm{~nm}$ a $8 \mu \mathrm{m}$, por meio de espalhamento de luz dinâmico, que é a medição de flutuações na intensidade de luz dispersa com o tempo. A leitura ocorreu através do movimento Browniano das partículas em um dispersante de sílica coloidal. Os pHs das amostras foram medidos utilizando um pHmetro de bancada, Logen mPA 210, mostrando simultaneamente o $\mathrm{pH}$ (escala de 0 a 14) e as temperaturas de cada solução em análise. No preparo de cada solução foram utilizados $10 \mathrm{~mL}$ de água deionizada ou destilada em um béquer de $20 \mathrm{~mL}$ e adicionados cerca de $0,004 \mathrm{~g}$ da amostra, agitando por $5 \mathrm{~min}$.

Para avaliação da atividade catalítica, as amostras foram testadas nas reações de esterificação do óleo de algodão em presença de etanol (como agente de alcoólise). A escolha do etanol foi com o objetivo de obter um combustível totalmente renovável, já que o metanol é proveniente de fontes não renováveis, a exemplo do petróleo. No processo da esterificação, foram utilizados $30 \mathrm{~g}$ de uma fonte lipídica, composta de óleo de algodão refinado $(0,4 \mathrm{mg} \mathrm{KOH} / \mathrm{g})$, adquirido em comércio local, com ácido oleico. Essa mistura simulou um óleo residual com índice de acidez de $15 \%$ em ácido oleico [24]. A quantidade das amostras testadas como catalisadores foi calculada em relação à massa da mistura (75\% de óleo algodão e 15\% de ácido oleico). As condições reacionais para síntese do biodiesel estão apresentadas na Tabela II. Os testes foram realizados em triplicata e foram conduzidos em um reator de aço inoxidável, o qual encamisou um copo de borossilicato de volume útil de $80 \mathrm{~mL}$, pressurizado, composto de um duto para entrada de termopar e acoplado a um manômetro. A agitação e o aquecimento do sistema foram promovidos por uma placa de aquecimento e agitação magnética. O produto reacional, obtido na reação de esterificação, foi reservado em um funil de decantação para a separação de fase e lavagem com água destilada. Finalizada a lavagem, o produto reacional foi encaminhado a uma centrifugação por $10 \mathrm{~min}$ a 9000 rpm, com a finalidade de separar resíduos de água e/ou catalisador sólido remanescente. Com a conclusão dessa etapa, o produto reacional foi acondicionado e conservado em geladeira entre 6 e $10{ }^{\circ} \mathrm{C}$. Os produtos obtidos na reação de esterificação foram analisados em cromatógrafo a gás

Tabela II - Condição reacional utilizada na esterificação do óleo de algodão em presença de etanol. [Table II - Reaction conditions used in the esterification of cottonseed oil in the presence of ethanol.]

\begin{tabular}{ccccc}
\hline $\begin{array}{c}\text { Velocidade de } \\
\text { agitação }(\mathrm{rpm})\end{array}$ & $\begin{array}{c}\text { Temperatura } \\
\left({ }^{\circ} \mathrm{C}\right)\end{array}$ & $\begin{array}{c}\text { Quantidade de } \\
\text { catalisador }(\%)\end{array}$ & $\begin{array}{c}\text { Relação óleo/ } \\
\text { álcool }\end{array}$ & $\begin{array}{c}\text { Tempo de reação } \\
(\mathrm{h})\end{array}$ \\
\hline 1000 & 180 & 2 & $1: 12$ & 3 \\
\hline
\end{tabular}


Varian 450c com detector de ionização de chamas (FID), coluna capilar de fase estacionária Varian Select Biodiesel Glycerides + RG (Ultimetal, $15 \mathrm{~m}$ x 0,32 $\mathrm{mm} \times 0,45 \mu \mathrm{m}$ ). A temperatura inicial para a injeção foi de $100{ }^{\circ} \mathrm{C}$ e a do forno foi de $180{ }^{\circ} \mathrm{C}$. O detector operou a $380{ }^{\circ} \mathrm{C}$. As amostras foram pesadas (cerca de $50 \mathrm{mg}$ ) em um frasco de $10 \mathrm{~mL}$ e posteriormente diluídas com n-hexano 97\% padrão UV/ HPLC. Logo em seguida, foram injetadas com auxílio de uma microsseringa de $1 \mu \mathrm{L}$ da solução preparada (amostra + solvente).

\section{RESULTADOS E DISCUSSÃO}

A Fig. 1 apresenta os difratogramas de raios $\mathrm{X}$ para as amostras de $\mathrm{ZrO}_{2}$ antes e após a sulfatação. Pôde-se observar que $\mathrm{o} \mathrm{ZrO}_{2}$ sintetizado mostrou a formação da fase majoritária monoclínica (JCPDF 65-2357) com traço da fase ortorrômbica (JCPDF 79-1796), com tamanho de cristalito de $16 \mathrm{~nm}$ e cristalinidade de $57 \%$. Na amostra de $\mathrm{ZrO}_{2}$ comercial foi identificada apenas a fase única monoclínica com tamanho de cristalito de $39 \mathrm{~nm}$ e cristalinidade de $86 \%$. Comparando os difratogramas na Fig. 1a, observou-se que o $\mathrm{ZrO}_{2}$ sintetizado possuiu picos com maior largura basal e deslocamento nos picos de difração, quando comparado com a largura basal dos picos de difração do $\mathrm{ZrO}_{2}$ comercial. O deslocamento observado foi em torno de $0,96^{\circ}$ para ângulos maiores, conforme pode ser visto de forma mais evidente no espectro ampliado na Fig. 1a e que pode estar relacionado ao surgimento de uma segunda fase metaestável do $\mathrm{ZrO}_{2}$ ortorrômbico durante a reação de combustão. $\mathrm{Na}$ ampliação, ficou também evidenciada a presença de traços da fase ortorrômbica, entre os dois picos principais do $\mathrm{ZrO}_{2}$ sintetizado, o que indicou uma transição de fase metaestável entre a zircônia monoclínica e tetragonal, o que não foi observado para o $\mathrm{ZrO}_{2}$ comercial.

$\mathrm{Na}$ Fig. 1b, têm-se os difratogramas de raios $\mathrm{X}$ para as amostras de $\mathrm{ZrO}_{2}$ sulfatadas $\left(\mathrm{SO}_{4}{ }^{2-}-\mathrm{ZrO}_{2}\right)$, em que foi verificado o surgimento de traços da fase tetragonal (JCPDF 79-1769), típico para o $\mathrm{ZrO}_{2}$, com a permanência da fase majoritária monoclínica. A fase de transição ortorrômbica não mais apareceu no $\mathrm{ZrO}_{2}$ sintetizado, quando o mesmo sofreu sulfatação. Por outro lado, o $\mathrm{ZrO}_{2}$ comercial, que antes apresentava apenas a fase monoclínica, após sulfatação apresentou traços da $\mathrm{ZrO}_{2}$ tetragonal. Essa mudança na estrutura das amostras de $\mathrm{ZrO}_{2}$, após sulfatação, foi consequência da temperatura de calcinação de $600^{\circ} \mathrm{C}$ por $3 \mathrm{~h}$ utilizada para sulfatação, pois essa energia térmica foi suficiente para prover a mudança estrutural e crescimento dos cristais nas amostras de $\mathrm{ZrO}_{2}$, tanto sintetizada como comercial. A literatura [4, 25-27] reporta que na transição de fase do $\mathrm{ZrO}_{2}$ monoclínico pode ocorrer o surgimento de uma fase metaestável, que é a fase tetragonal, e que essa transição é influenciada pelas condições do método de síntese utilizado e a sulfatação das amostras de $\mathrm{ZrO}_{2}$. Na comparação dos difratogramas de raios $\mathrm{X}$ na Fig. 1b, ficou evidenciado que o $\mathrm{ZrO}_{2}$ sintetizado e sulfatado com $30 \%$ de $\mathrm{SO}_{4}{ }^{2-}$ também apresentou picos com maior largura basal
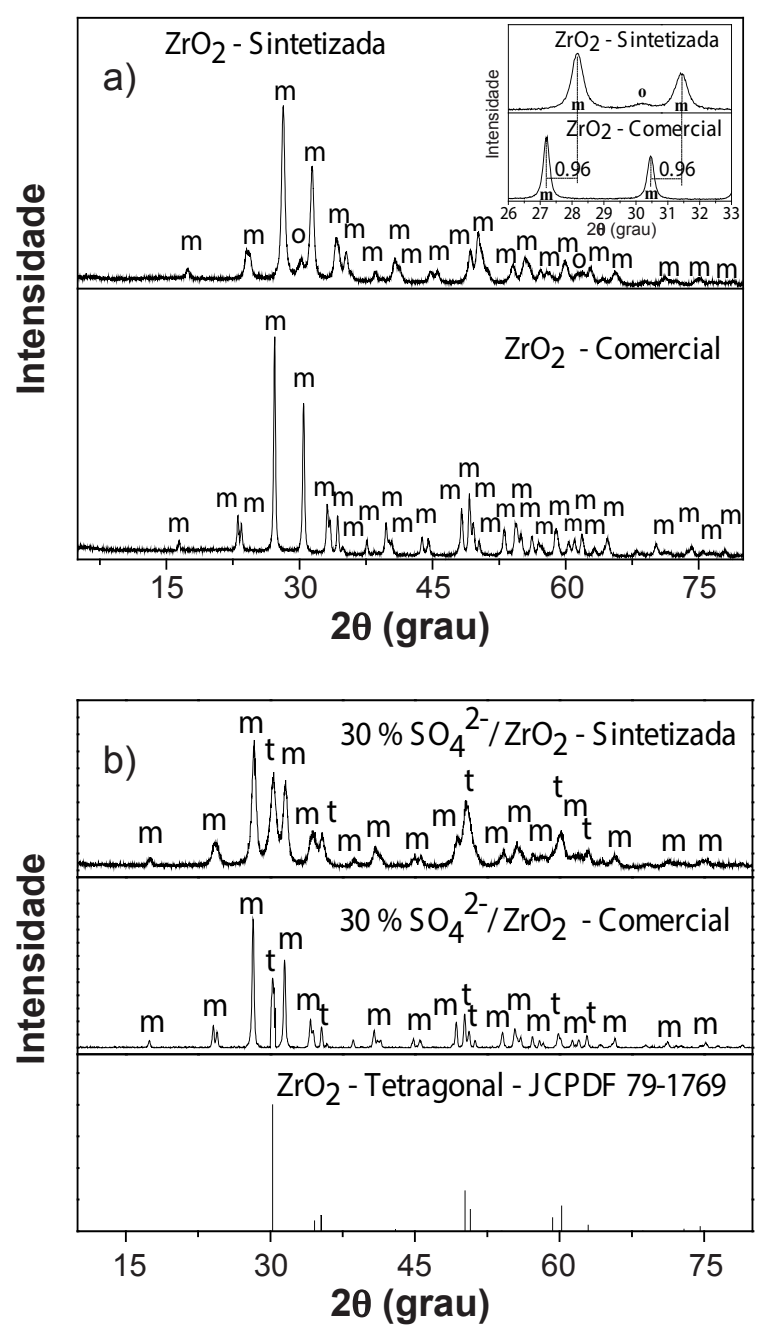

Figura 1: Difratogramas de raios $\mathrm{X}$ de: (a) amostras de $\mathrm{ZrO}_{2}$ sintetizado e comercial, com ampliação na faixa de 26 a $33^{\circ}$; (b) amostras sulfatadas $\mathrm{SO}_{4}^{2-} / \mathrm{ZrO}_{2}$ comercial e sintetizada.

[Figure 1: X-ray diffraction patterns of: (a) synthesized and commercial $\mathrm{ZrO}$, samples, with enlargement in the range from 26 to $33^{\circ}$; (b) commercial and synthesized $\mathrm{SO}_{4}{ }^{2-} / \mathrm{ZrO}_{2}$ sulfated samples.]

do que o $\mathrm{ZrO}_{2}$ comercial com o mesmo teor de sulfactante, mas sem deslocamento nos picos de difração, como ocorreu no $\mathrm{ZrO}_{2}$ sintetizado e comercial sem sulfatação (Fig. 1a). Os tamanhos de cristalitos e as cristalinidades resultaram em diminuição dos seus valores com a sulfatação, apresentando tamanho de cristalito de $15,9 \mathrm{~nm}$ e cristalinidade de $44,1 \%$ para o $\mathrm{SO}_{4}^{2-} / \mathrm{ZrO}_{2}$ sintetizado e tamanho de cristalito $26,8 \mathrm{~nm}$ e cristalinidade $67,0 \%$ para o $\mathrm{SO}_{4}^{2-} / \mathrm{ZrO}_{2}$ comercial.

A Fig. 2 apresenta espectros DE FTIR do $\mathrm{ZrO}_{2}$ sintetizado e comercial. Na Fig. 2a, são verificadas duas bandas de adsorção entre 3200 e $2700 \mathrm{~cm}^{-1}$ que podem ser atribuídas aos estiramentos de $\mathrm{O}-\mathrm{H}$ das moléculas de água adsorvidas [4, 28]. Os picos agudos em torno de $1452 \mathrm{~cm}^{-1}$ e entre 2700-3000 $\mathrm{cm}^{-1}$ foram atribuídos às bandas vibracionais de alongamentos das cadeias de hidrocarbonetos $\mathrm{CH}_{\text {e }} \mathrm{CH}_{3}[29,30]$. A banda em torno de $2340 \mathrm{~cm}^{-1}$ foi atribuída aos grupos de $\mathrm{CO}_{2}$ devido à decomposição do precursor isopropóxido de zircônio, $\mathrm{Zr}\left(\mathrm{OCH}_{2} \mathrm{CH}_{2} \mathrm{CH}_{3}\right)_{4}$, e ela foi reportada em [31] quando o 

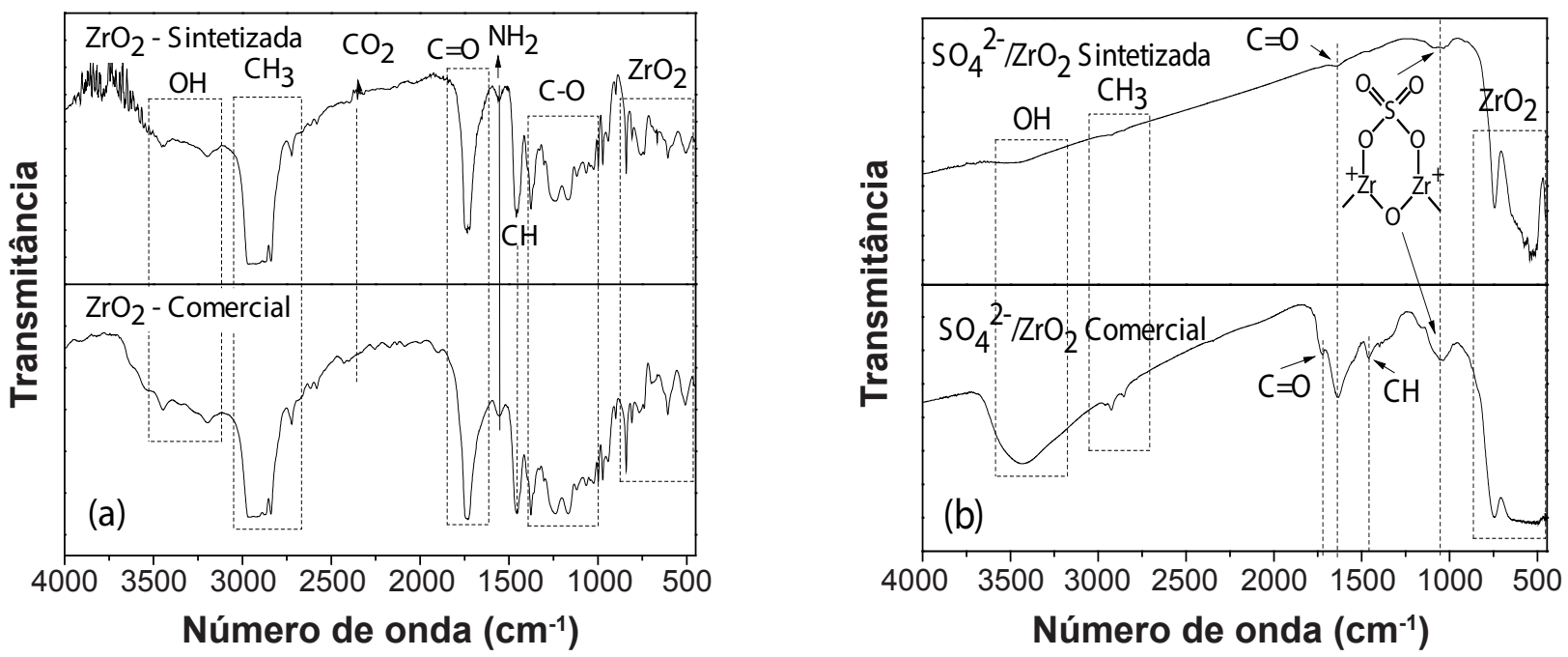

Figura 2: Espectros de FTIR de: (a) $\mathrm{ZrO}_{2}$ como sintetizado e comercial; (b) zircônias sulfatadas $\mathrm{SO}_{4}^{2-} / \mathrm{ZrO}_{2}$ sintetizada e comercial. [Figure 2: FTIR spectra of: (a) as-synthesized and commercial $\mathrm{ZrO}_{2}$; (b) synthesized and commercial sulfated zirconia $\left.\mathrm{SO}_{4}^{2-1} \mathrm{ZrO}_{2} \cdot\right]$

precursor $\mathrm{Zr}\left(\mathrm{OCH}_{2} \mathrm{CH}_{2} \mathrm{CH}_{3}\right)_{4}$ também foi utilizado para síntese da $\mathrm{ZrO}_{2}$ pelo método sol-gel. As bandas em torno de $1567 \mathrm{e} 1750 \mathrm{~cm}^{-1}$ corresponderam à vibração e deformação de $\mathrm{NH}_{2}$ (resquício de ureia no caso da sintetização) e vibração de alongamento de $\mathrm{C}=\mathrm{O}$. As bandas entre $1300 \mathrm{e}$ $1000 \mathrm{~cm}^{-1}$ são características de alongamentos vibracionais de $\mathrm{C}-\mathrm{O}$ e as bandas localizadas em torno de $800-500 \mathrm{~cm}^{-1}$ corresponderam aos modos de estiramento de $\mathrm{Zr}-\mathrm{O}_{2}-\mathrm{Zr}$ e assimetria $\mathrm{Zr}-\mathrm{O}$, o que confirmou a formação de fases de $\mathrm{ZrO}_{2}$. Todas essas bandas foram relatadas na literatura [4, $15,30,32,33]$, quando reportaram a síntese do $\mathrm{ZrO}_{2}$ pelos métodos de síntese de combustão, Pechini e sulfatação.

$\mathrm{Na}$ Fig. $2 \mathrm{~b}$ encontram-se os espectros vibracionais de infravermelho das zircônias sulfatadas $\left(\mathrm{SO}_{4}^{2-} / \mathrm{ZrO}_{2}\right)$. Semelhantemente à análise feita na Fig. 2a, observou-se uma banda aguda de adsorção entre 3200 e $2700 \mathrm{~cm}^{-1}$ que pode ser atribuída ao estiramento de $\mathrm{O}-\mathrm{H}$ das moléculas de água adsorvidas. Outros dois pequenos picos entre $2700 \mathrm{e}$ $3000 \mathrm{~cm}^{-1}$ foram atribuídos às bandas vibracionais da cadeia de hidrocarbonetos $\mathrm{CH}_{3}$. As bandas em torno de 1736 e 1637 $\mathrm{cm}^{-1}$ corresponderam ao alongamento de $\mathrm{C}=\mathrm{O}$, enquanto a banda em torno de $1466 \mathrm{~cm}^{-1}$ referiu-se à vibração de mais um hidrocarboneto CH. Segundo [34], em estudo sobre a zircônia sulfatada pela rota sol-gel, os picos entre $1000 \mathrm{e}$ $1250 \mathrm{~cm}^{-1}$ foram atribuídos às bandas de vibrações de $\mathrm{SO}_{4}{ }^{2-}$ das zircônias sulfatadas. Já as bandas localizadas em torno de $800-500 \mathrm{~cm}^{-1}$ corresponderam aos modos de estiramento de $\mathrm{Zr}-\mathrm{O}_{2}-\mathrm{Zr}$ e assimetria $\mathrm{Zr}-\mathrm{O}$, o que confirmou a formação de fases $\mathrm{ZrO}_{2}$, conforme mencionado anteriormente na Fig. 2a.

Mediante a Fig. 3 da distribuição granulométrica, foi possível observar a distribuição do tamanho dos diâmetros esféricos das partículas das amostras de $\mathrm{ZrO}_{2}$, antes e após a sulfatação. Foi observado que todas as amostras apresentaram comportamento simétrico e monomodal. A amostra comercial apresentou a distribuição de partículas mais estreita (Fig. 3b), enquanto a amostra comercial sulfatada apresentou a distribuição de partículas mais larga (Fig. 3d). Com relação ao tamanho mediano das partículas, $d_{50 \%}$, ficou evidenciado um tamanho maior para a amostra comercial, seja ela pura ou sulfatada. A Tabela III mostra os resultados da distribuição granulométrica das amostras de $\mathrm{ZrO}_{2}$, antes e após sulfatação, em que a faixa de distribuição se estendeu de $10 \mathrm{~nm}$ até aproximadamente $10000 \mathrm{~nm}$. Nessa faixa de distribuição, foi possível observar que ocorreu variação no diâmetro do tamanho de partícula considerável, tomando como referência o $\mathrm{ZrO}_{2}$ sintetizado (Fig. 3a) e comercial (Fig. 3b). Verificou-se, pela variação do tamanho médio dos diâmetros de partículas (TMP), que o $\mathrm{ZrO}_{2}$ sintetizado teve um crescimento de $47,6 \%$ em relação ao $\mathrm{SO}_{4}^{2-} / \mathrm{ZrO}_{2}$ sintetizado. No $\mathrm{ZrO}_{2}$ comercial o crescimento do tamanho médio dos diâmetros de partículas foi de $54,9 \%$. Isto pôde ser justificado pelo fato de o sulfato adentrar nos espaços entre os poros, adsorvendo na superfície da partícula. Além disso, a calcinação também influenciou no tamanho de partículas durante o processo de sulfatação de cada amostra de $\mathrm{ZrO}_{2}$. Como consequência, áreas superficiais e volumes de poros foram menores.

Na Fig. 4 encontram-se ilustradas as isotermas de adsorção/dessorção de $\mathrm{N}_{2}$ como resultado da caracterização textural das amostras de $\mathrm{ZrO}_{2}$, antes e após sulfatação, cuja temperatura máxima de combustão alcançada foi $690{ }^{\circ} \mathrm{C}$. Verificou-se que as isotermas de adsorção/dessorção das amostras foram compatíveis com o modelo tipo IV com loop de histerese do tipo $\mathrm{H} 1$, encontradas em materiais cujos poros são regulares, segundo a classificação de BrunauerEmmett-Teller (BET) [4, 35-37]. Mediante a literatura [38], as isotermas de adsorção/dessorção do tipo IV são típicas de materiais mesoporosos e a histerese do tipo H1 está associada a materiais porosos constituídos por aglomerados de partículas esféricas de tamanho uniforme, referenciado para isso a nomenclatura da IUPAC [39].

A Tabela IV apresenta os valores de área superficial específica $\left(\mathrm{S}_{\mathrm{BET}}\right)$, tamanho de partícula $\left(\mathrm{D}_{\mathrm{BET}}\right)$, volume 

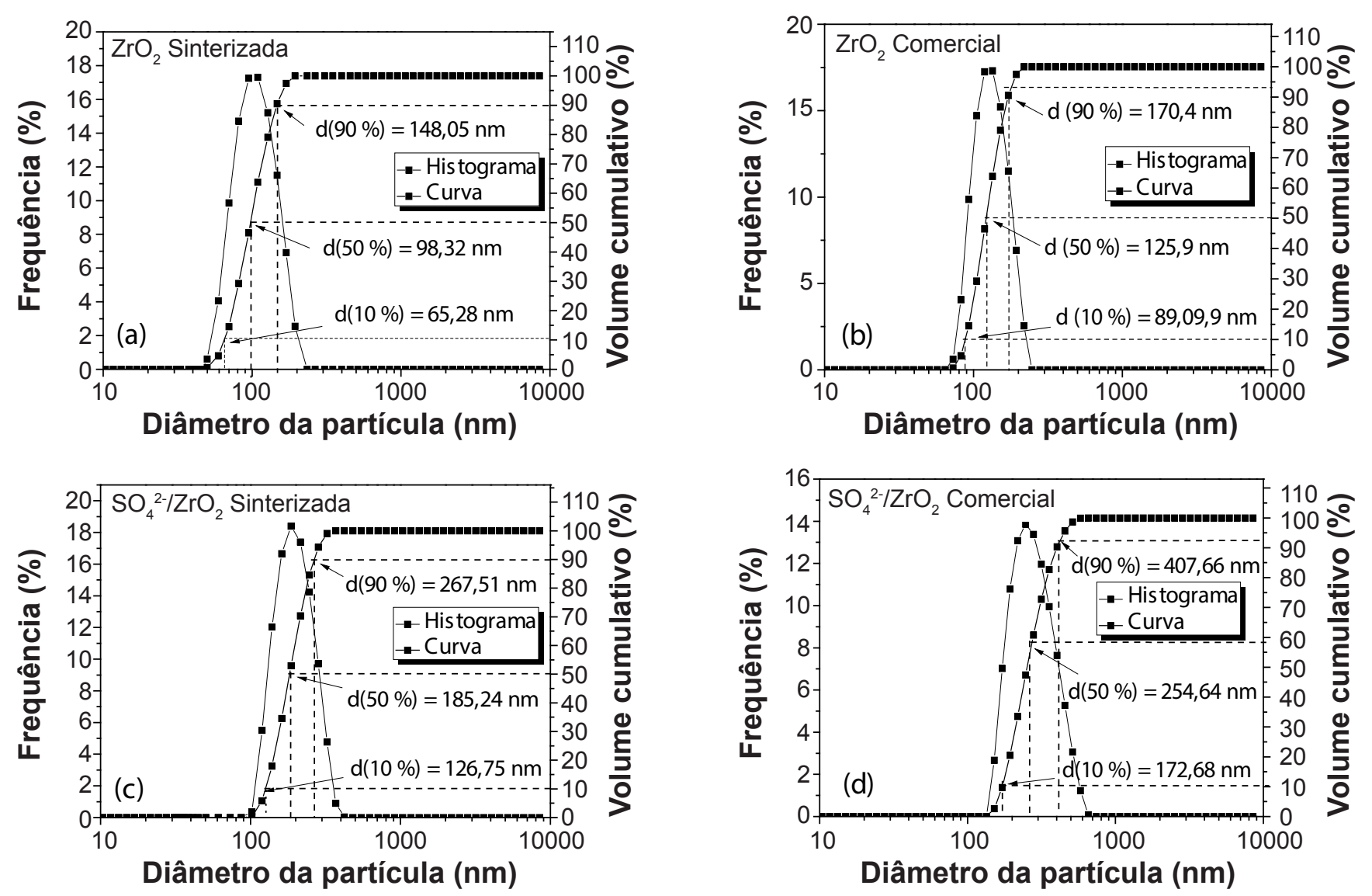

Figura 3: Distribuição granulométrica de: (a) $\mathrm{ZrO}_{2}$ sintetizado, (b) $\mathrm{ZrO}_{2}$ comercial, (c) $\mathrm{SO}_{4}^{2-} / \mathrm{ZrO}_{2}$ sintetizado e (d) $\mathrm{SO}_{4}^{2-} / \mathrm{ZrO}_{2}$ comercial. [Figure 3: Particle size distribution curves of: (a) synthesized $\mathrm{ZrO}_{2}$, (b) commercial $\mathrm{ZrO}_{2}$, (c) synthesized $\mathrm{SO}_{4}^{2-} / \mathrm{ZrO}_{2}$, and (d) commercial $\mathrm{SO}_{4}^{2-} / \mathrm{ZrO}_{2}$.]

do poro $\left(\mathrm{V}_{\mathrm{p}}\right)$ e diâmetro de poro $\left(\mathrm{D}_{\mathrm{p}}\right)$ para as amostras de $\mathrm{ZrO}_{2}$ como sintetizada e comercial, bem como as sulfatadas $\mathrm{SO}_{4}^{2-} / \mathrm{ZrO}_{2}$ sintetizada e comercial. Pôde-se observar que a maior área superficial específica foi obtida para o $\mathrm{ZrO}_{2}$ sintetizado por reação de combustão, sendo $50 \%$ maior que a área superficial do $\mathrm{ZrO}_{2}$ comercial, $72 \%$ maior que a área superficial do $\mathrm{SO}_{4}^{2-} / \mathrm{ZrO}_{2}$ (sintetizado) e por fim $78 \%$ maior que a área superficial do $\mathrm{SO}_{4}{ }^{2-} / \mathrm{ZrO}_{2}$ comercial. Os resultados de tamanho de partículas evidenciaram que a amostra sintetizada por reação de combustão apresentou tamanho de partícula 51\% menor que o tamanho de partícula do $\mathrm{ZrO}_{2}$ comercial, $72 \%$ menor que o tamanho de partícula do $\mathrm{SO}_{4}{ }^{2-} / \mathrm{ZrO}_{2}$ (sintetizado) e $80 \%$ menor que o tamanho de partícula do $\mathrm{SO}_{4}{ }^{2-} / \mathrm{ZrO}_{2}$ (comercial). Outro fator que influenciou o tamanho da partícula foi o processo de sulfatação acrescido de calcinação, visto que a temperatura promoveu o crescimento dos cristais, associado com o íon $\mathrm{SO}_{4}^{2-}$ adsorvido na superfície das partículas. Esse fato reduziu a área de superfície e aumentou o tamanho da partícula, consequentemente diminuiu o tamanho e o volume dos poros. Os valores do tamanho de partícula foram em concordância com os resultados obtidos para tamanho de cristalito, pois o tamanho de partícula menor significa uma área superficial maior. Com relação aos resultados de tamanho de partícula/tamanho de cristalito $\left(\mathrm{D}_{\mathrm{BET}} / \mathrm{T}_{\mathrm{C}}\right)$, observou-se pequeno aumento referente às amostras de $\mathrm{ZrO}_{2}$ sulfatadas, indicando assim que as amostras sulfatadas foram mais policristalinas, ou seja, com a presença de mais cristais por partículas, e que se encontraram mais aglomeradas. Dessa forma, as amostras sem sulfatação apresentaram

Tabela III - Valores de diâmetro de partículas em 10, 50 e 90\% e tamanho médio de partícula (MDP) das amostras de zircônia. [Table III - Particle diameter values in 10, 50 and $90 \%$ and average particle size (MDP) of zirconia samples.]

\begin{tabular}{ccccc}
\hline Amostra & $\mathrm{d}_{10 \%}(\mathrm{~nm})$ & $\mathrm{d}_{50 \%}(\mathrm{~nm})$ & $\mathrm{d}_{90 \%}(\mathrm{~nm})$ & $\mathrm{MDP}(\mathrm{nm})$ \\
\hline $\mathrm{ZrO}_{2}$ sintetizada & 65,3 & 98,3 & 148,1 & 106,0 \\
$\mathrm{ZrO}_{2}$ comercial & 89,1 & 125,9 & 170,4 & 132,0 \\
$\mathrm{SO}_{4}{ }^{2-} / \mathrm{ZrO}_{2}$ sintetizada & 128,8 & 185,2 & 287,6 & 196,5 \\
$\mathrm{SO}_{4}{ }^{2-} / \mathrm{ZrO}_{2}$ comercial & 172,7 & 254,6 & 407,7 & 272,8 \\
\hline
\end{tabular}



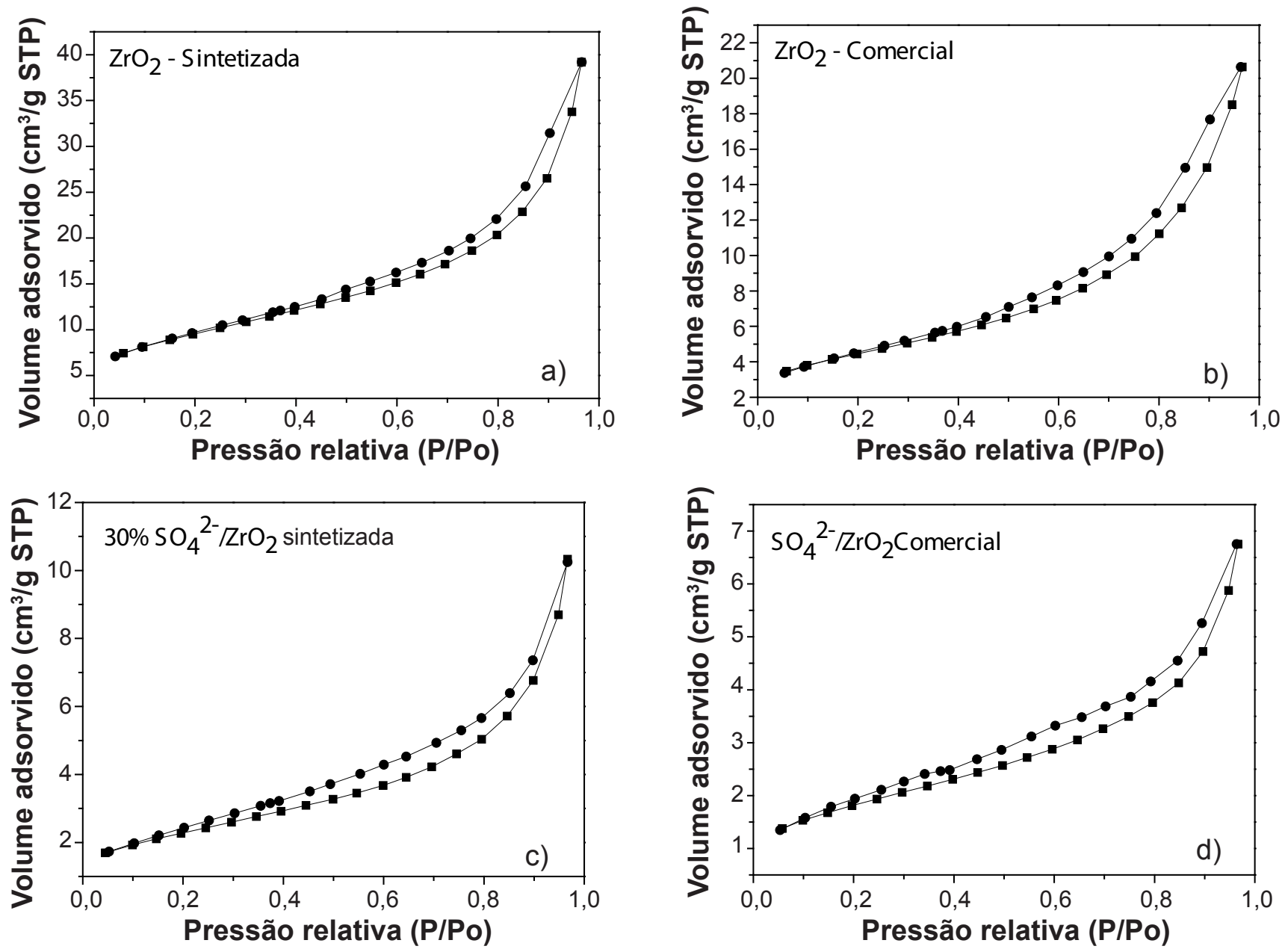

Figura 4: Isotermas de adsorção/dessorção das amostras de $\mathrm{ZrO}_{2}$ : (a) sintetizada, (b) comercial, (c) $\mathrm{SO}_{4}{ }^{2-} / \mathrm{ZrO}_{2}$ sintetizada e (d) $\mathrm{SO}_{4}{ }^{2-} / \mathrm{ZrO}_{2}$ comercial.

[Figure 4: Adsorption/desorption of $\mathrm{ZrO}_{2}$ : (a) synthesized, (b) commercial, (c) synthesized $\mathrm{SO}_{4}^{2-} / \mathrm{ZrO}_{2}$, and (d) commercial $\mathrm{SO}_{4}^{2-} / \mathrm{ZrO}_{2} \cdot$ ]

partículas mais finas do que as amostras sulfatadas e menos aglomeradas. É possível observar também nos resultados da Tabela IV que as amostras apresentaram características de um material com mesoporosidade, isto é, o diâmetro dos poros se localizou no intervalo de 2 a $50 \mathrm{~nm}$. De acordo com estudos reportados na literatura, os poros são classificados de acordo com os seguintes tamanhos: microporos, quando o diâmetro for menor do que $2 \mathrm{~nm}$; mesoporos, quando o diâmetro estiver classificado entre 2 e $50 \mathrm{~nm}$; e macroporos, quando o diâmetro for maior do que $50 \mathrm{~nm}$ [4, 36, 37].

A Fig. 5 ilustra as micrografias para as amostras de $\mathrm{ZrO}_{2}$ antes e após sulfatação. Para todas amostras, observou-se morfologia homogênea, constituída de partículas muito finas de formato aproximadamente esférico [1]. Na Fig. 5a, verifica-se que o $\mathrm{ZrO}_{2}$ sintetizado apresentou morfologia constituída de partículas com tamanho variando entre 8 e $70 \mathrm{~nm}$, com tamanho médio de $42 \mathrm{~nm}$. Enquanto que para o $\mathrm{ZrO}_{2}$ comercial, Fig. 5b, observa-se uma morfologia formada por partículas de tamanhos maiores, variando entre 47 e $117 \mathrm{~nm}$, com tamanho médio de $72 \mathrm{~nm}$. Comparando a morfologia das amostras, verificou-se que o $\mathrm{ZrO}_{2}$ sintetizado apresentou tamanho de partícula médio $42 \%$ inferior ao do
$\mathrm{ZrO}_{2}$ comercial. Isso evidenciou a eficiência da síntese de reação de combustão na produção em bateladas de $15 \mathrm{~g}$ de nanopartículas de $\mathrm{ZrO}_{2}$. Para as amostras sulfatadas $\left(\mathrm{SO}_{4}{ }^{2-}\right.$ $\mathrm{ZrO}_{2}$ sintetizado e comercial), Figs. 5c e 5d, observouse morfologia com partículas esféricas, semelhantemente à amostra de $\mathrm{ZrO}_{2}$ não sulfatadas (Figs. 5a e 5b), porém com partículas com menor porosidade interpartícula, o que pode estar relacionado ao íon $\mathrm{SO}_{4}{ }^{2-}$ que foi adsorvido sobre a superfície das partículas, reduzindo a porosidade interpartícula e o diâmetro dos poros. Na Fig. 5c, para o $\mathrm{SO}_{4}{ }^{2-} / \mathrm{ZrO}_{2}$ sintetizado, verificou-se morfologia constituída de partículas com tamanho variando entre 75 e $170 \mathrm{~nm}$ e tamanho médio de $113 \mathrm{~nm}$. Para o $\mathrm{SO}_{4}^{2-/} / \mathrm{ZrO}_{2}$ comercial (Fig. 5d), observou-se morfologia com partículas maiores do que as demais (Figs. 5a a 5c), variando entre 80 e $210 \mathrm{~nm}$ e tamanho médio de $146 \mathrm{~nm}$.

A Fig. 6 ilustra as curvas de TG, DrTG e DTA do $\mathrm{ZrO}_{2}$ antes e após sulfatação. Mediante a Fig. 6a foram observados picos endotérmicos a $97{ }^{\circ} \mathrm{C}$ (DTA) e $205{ }^{\circ} \mathrm{C}$ (DrTG) correspondentes a um somatório de perda de massa de 10,25\%, relacionado à perda de água fisicamente adsorvida, ou seja, a desidratação da amostra de $\mathrm{ZrO}_{2}$ que 
Tabela IV - Valores de área superficial específica $\left(\mathrm{S}_{\mathrm{BET}}\right)$, tamanho de partícula $\left(\mathrm{D}_{\mathrm{BET}}\right)$, volume de poro $\left(\mathrm{V}_{\mathrm{P}}\right)$, diâmetro de poro $\left(\mathrm{D}_{\mathrm{P}}\right)$, tamanho de cristalito $\left(\mathrm{T}_{\mathrm{c}}\right)$ e relação $\mathrm{D}_{\mathrm{BET}} / \mathrm{T}_{\mathrm{C}}$ das amostras de $\mathrm{ZrO}_{2}$, sintetizadas por reação de combustão e comercial.

[Table IV - Values of the specific surface area $\left(S_{B E T}\right)$, particle size $\left(D_{B E T}\right)$, pore volume $\left(V_{P}\right)$, pore diameter $\left(D_{P}\right)$, crystallite size $(T)$, and $D_{B E T} / T_{C}$ ratio of the synthesized $\mathrm{ZrO}_{2}$ samples by combustion reactions and the commercial one.]

\begin{tabular}{ccccccc}
\hline Amostra & $\mathrm{S}_{\mathrm{BET}}\left(\mathrm{m}^{2} \cdot \mathrm{g}^{-1}\right)$ & $\mathrm{D}_{\mathrm{BET}}{ }^{*}(\mathrm{~nm})$ & $\mathrm{V}_{\mathrm{P}}\left(\mathrm{cm}^{3} / \mathrm{g}\right)$ & $\mathrm{D}_{\mathrm{P}}(\mathrm{nm})$ & $\mathrm{T}_{\mathrm{c}}(\mathrm{nm})$ & $\mathrm{D}_{\mathrm{BET}} / \mathrm{T}_{\mathrm{C}}$ \\
\hline $\mathrm{ZrO}$ sintetizada & 35,57 & 30 & 0,058 & 3,82 & 16,00 & 1,87 \\
$\mathrm{ZrO}_{2}$ comercial & 17,59 & 61 & 0,031 & 3,84 & 39,00 & 1,56 \\
$\mathrm{SO}_{4}{ }^{2}-/ \mathrm{ZrO}_{2}$ sintetizada & 9,91 & 108 & 0,015 & 2,36 & 15,85 & 6,81 \\
$\mathrm{SO}_{4}{ }^{2-} / \mathrm{ZrO}_{2}$ comercial & 7,77 & 149 & 0,010 & 2,46 & 26,76 & 5,57 \\
\hline
\end{tabular}

* - calculado a partir dos dados da área superficial.

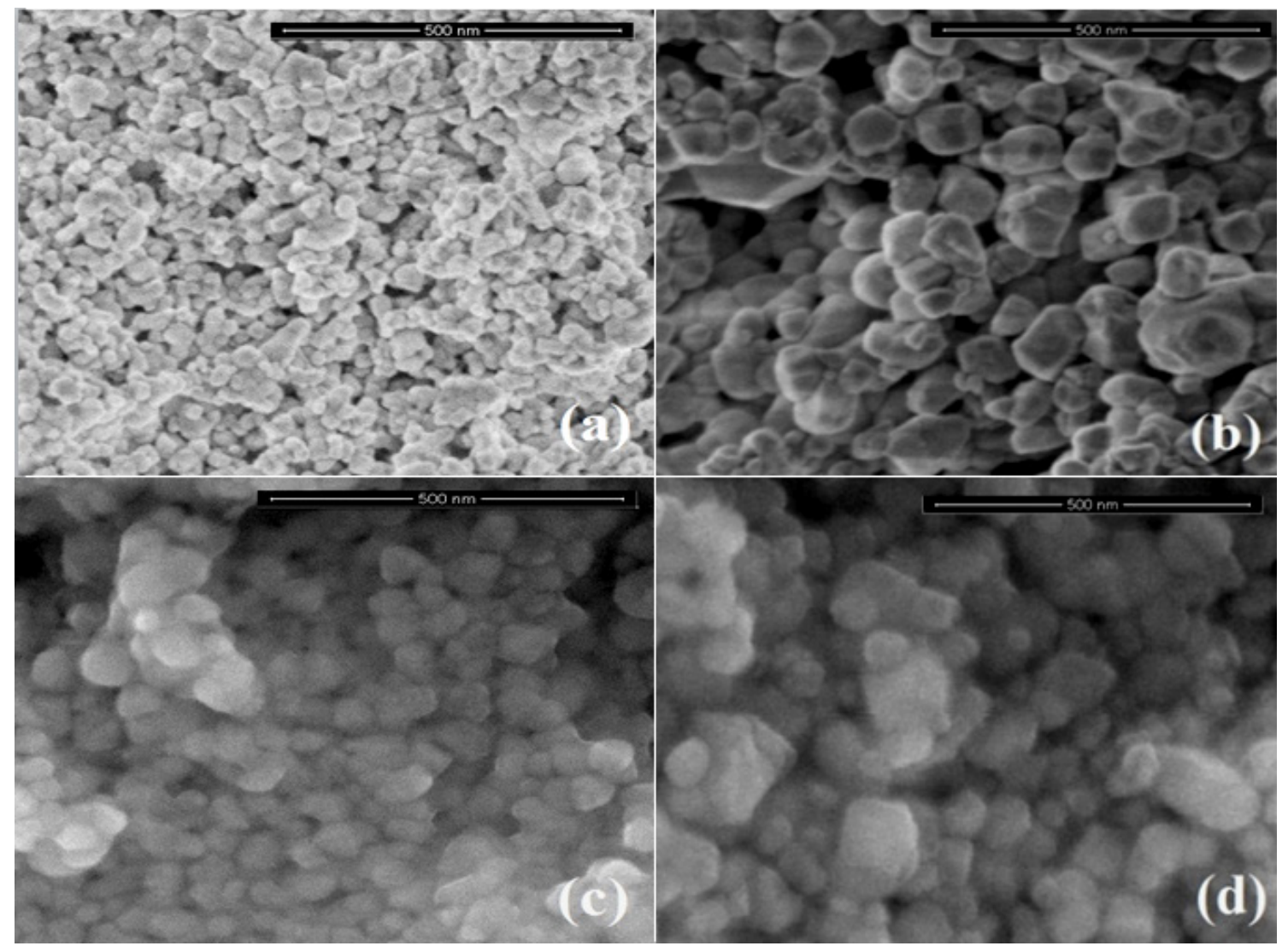

Figura 5: Micrografias obtidas por microscopia eletrônica de varredura de: (a) $\mathrm{ZrO}_{2}$ sintetizado, (b) $\mathrm{ZrO}_{2}$ comercial, (c) $\mathrm{SO}_{4}^{2-} / \mathrm{ZrO}_{2}$ sintetizado e (d) $\mathrm{SO}_{4}^{2-} / \mathrm{ZrO}_{2}$ comercial.

[Figure 5: SEM micrographs of: (a) synthesized $\mathrm{ZrO}_{2}$, (b) commercial $\mathrm{ZrO}_{2}$, (c) synthesized $\mathrm{SO}_{4}^{2-} / \mathrm{ZrO}_{2}$, and (d) commercial $\mathrm{SO}_{4}^{2-} / \mathrm{ZrO}_{2}$.]

ocorreu durante o processo de aquecimento. $\mathrm{O}$ terceiro pico em torno de $306{ }^{\circ} \mathrm{C}$ (DrTG) com perda de massa de $4,93 \%$ pode ser atribuído a resíduos de ureia provenientes do processo de combustão, conforme mencionado em [40] sobre o comportamento térmico do $\mathrm{ZrO}_{2}$ tetragonal, sintetizado por reação de acoplamento; também observou perda de massa em torno $300{ }^{\circ} \mathrm{C}$, atribuída à decomposição de resíduos orgânicos presentes na composição do material. O pico endotérmico em torno de $412{ }^{\circ} \mathrm{C}$ (DTA), com perda de massa de $21,23 \%$, e o pico exotérmico em torno de 555 ${ }^{\circ} \mathrm{C}$ (DTA), perda de massa de 22,3\%, decorreram de uma possível transformação de fase do $\mathrm{ZrO}_{2}$. Relacionando a Fig. 6a da análise térmica com a Fig. 1 do DRX, pôde-se concluir que se tratou da transformação de parte da $\mathrm{ZrO}_{2}$ monoclínica para traços de fase da $\mathrm{ZrO}_{2}$ ortorrômbica. Essa constatação também foi igualmente relatada em [35, 40, 41], quando avaliaram o $\mathrm{ZrO}_{2}$, sulfatado como catalisador em processo de análise do catalisador superácido, efeito da sulfatação da zircônia com a finalidade de obter a fase tetragonal e na reação de esterificação para se obter biodiesel.

A Fig. 6b ilustra as curvas TG/DrTG/DTA da amostra de $\mathrm{ZrO}_{2}$ comercial, que passou por um tratamento térmico até uma temperatura de $1000{ }^{\circ} \mathrm{C}$. Na curva de TG, notou-se uma perda de massa de $2,04 \%$ durante todo o processo de aquecimento da análise térmica. De acordo com a Fig. 6b, foi possível fazer uma análise dividida em três estágios. O 

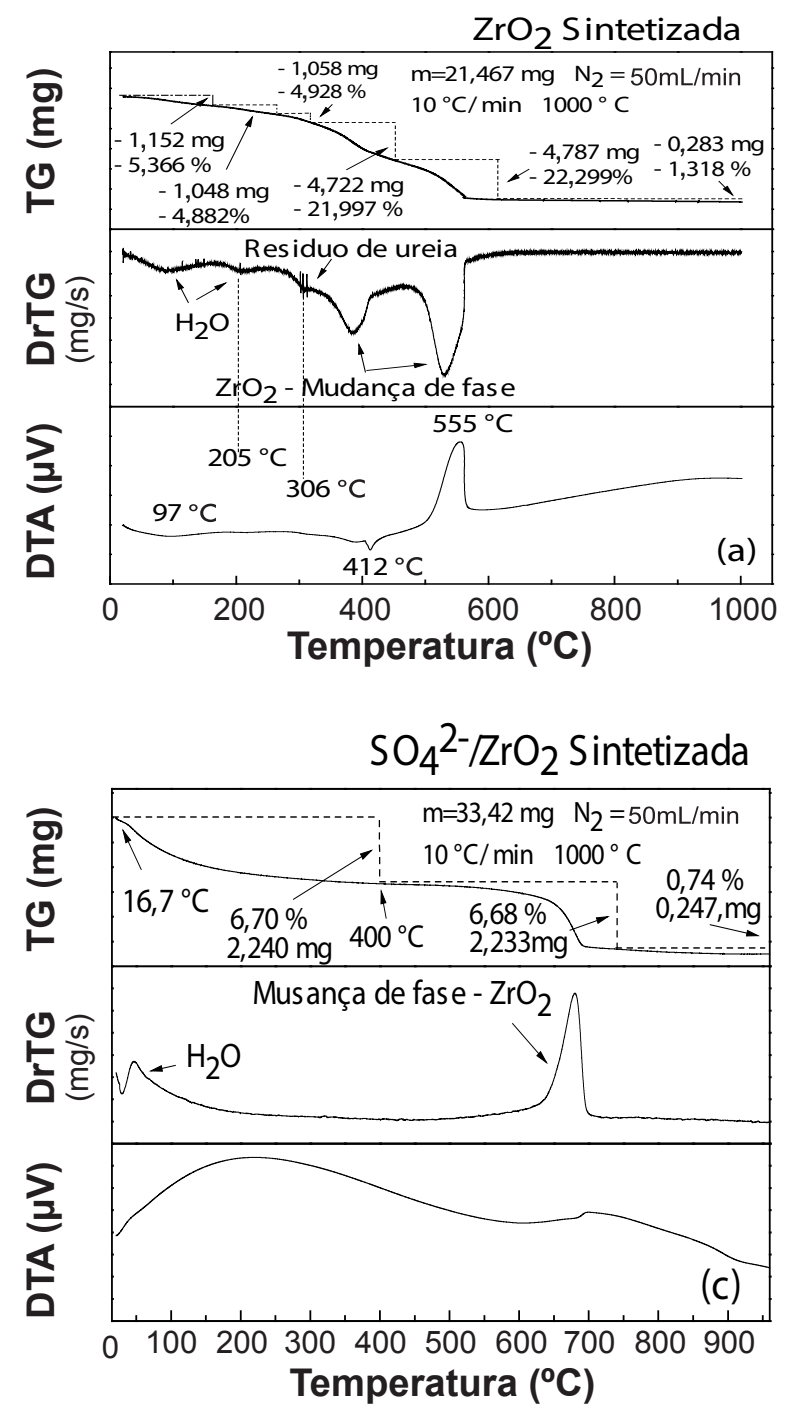
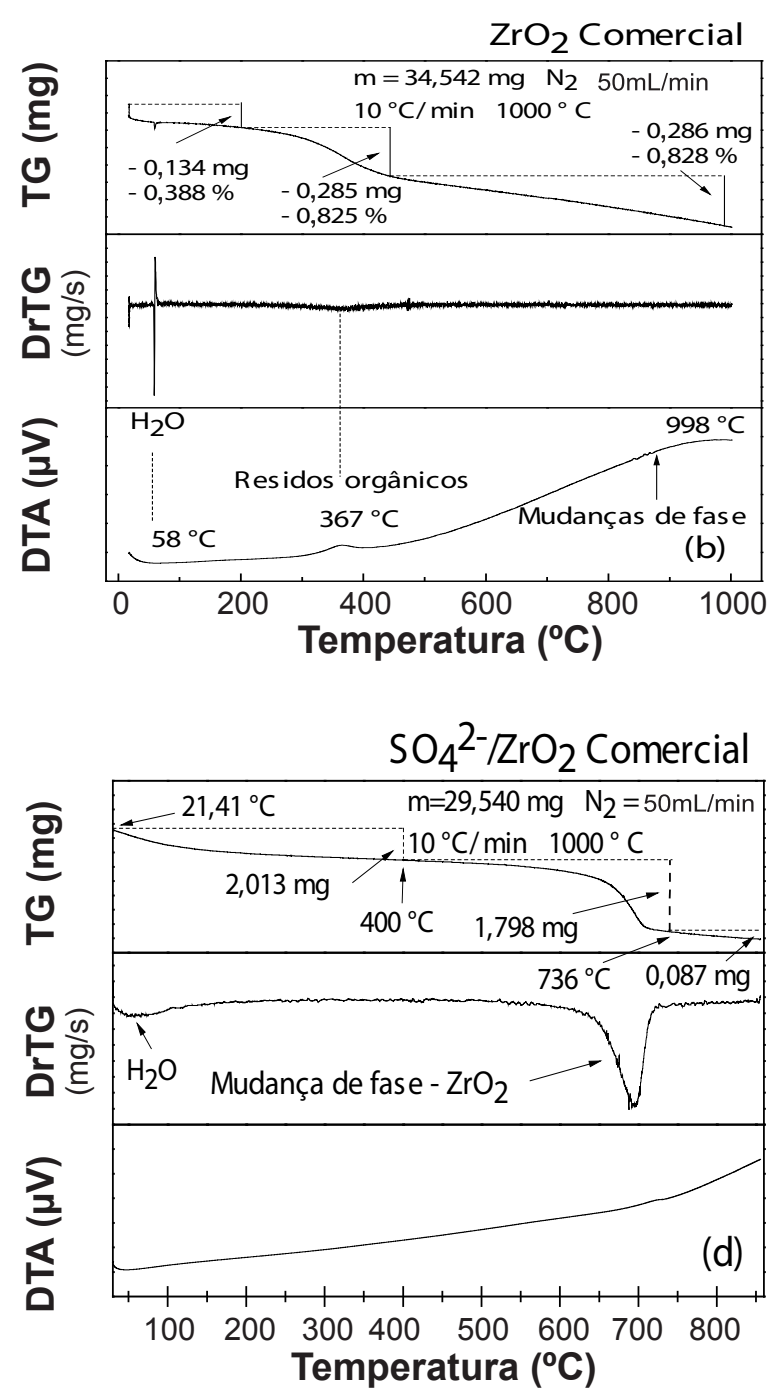

Figura 6: Curvas de TG, DrTG e DTA: (a) $\mathrm{ZrO}_{2}$ sintetizada, (b) comercial, (c) $\mathrm{SO}_{4}^{2-} / \mathrm{ZrO}_{2}$ sintetizada e (d) $\mathrm{SO}_{4}^{2-} / \mathrm{ZrO}_{2}$ comercial. [Figure 6: TG, DrTG and DTA curves: (a) synthesized $\mathrm{ZrO}_{2}$, (b) commercial (c) synthesized $\mathrm{SO}_{4}^{2-} / \mathrm{ZrO}_{2}$ and (d) commercial $\mathrm{SO}_{4}^{2-} / \mathrm{ZrO}_{2}$.]

primeiro estágio representado por um pico endotérmico (DTA/ DrTG $58^{\circ} \mathrm{C}$ ), com perda de massa de $0,39 \%$ foi correspondente à perda de água fisicamente adsorvida; o segundo e o terceiro estágios (DTA/DrTG $368^{\circ} \mathrm{C}$ e DTA $998^{\circ} \mathrm{C}$ ), considerados picos exotérmicos, foram relacionados a uma possível oxidação e decomposição de resíduos orgânicos (segundo pico) e a uma provável mudança de fase do $\mathrm{ZrO}_{2}$ (terceiro pico). O mesmo comportamento também foi observado na literatura [41], quando foi estudado o comportamento térmico do $\mathrm{ZrO}_{2}$ na fase tetragonal. As Figs. 6c e 6d apresentam características semelhantes com relação às curvas de TG, com uma perda da massa brusca entre 600 e $720{ }^{\circ} \mathrm{C}$, o que pode estar relacionada a uma mudança de fase para ambas as amostras de $\mathrm{ZrO}_{2}$ sulfatadas. Observou-se que a perda de massa nesse intervalo de temperatura foi de 2,233 mg para o $\mathrm{SO}_{4}{ }^{2-} / \mathrm{ZrO}_{2}$ sintetizado e de $1,798 \mathrm{mg}$ para o $\mathrm{SO}_{4}{ }^{2-} / \mathrm{ZrO}_{2}$ comercial. Com relação às curvas de DrTG, foi notório que ambos os picos evidenciaram a perda de massa com o aumento da temperatura. Quanto às curvas de DTA, ambas podem ter sofrido alterações durante o período de análise, com possíveis ruídos ou falhas no manuseio do equipamento, evitando assim uma leitura mais representativa.

A Tabela $\mathrm{V}$ mostra o $\mathrm{pH}$ e a temperatura das amostras de $\mathrm{ZrO}_{2}$ sintetizado, comercial e sulfatadas. Para a amostra $\mathrm{ZrO}_{2}$ sintetizado, contendo apenas água deionizada, observou-se um $\mathrm{pH}$ de 5,12. Na amostra $\mathrm{ZrO}_{2}$ comercial, o pH obtido nas mesmas condições de análise da amostra anterior foi de 4,92. Com a impregnação do íon sulfato $\mathrm{SO}_{3}$ na superfície das amostras de $\mathrm{ZrO}_{2}$ sintetizada e comercial, os novos valores apresentaram características ácidas mais acentuadas, apresentando $\mathrm{pH}$ de 3,21 para a amostra $\mathrm{SO}_{4}{ }^{2-} / \mathrm{ZrO}_{2}$ sintetizada e $\mathrm{pH}$ de 2,65 para a amostra $\mathrm{SO}_{4}{ }^{2-} / \mathrm{ZrO}_{2}$ comercial, o que demonstrou aumento de acidez das amostras quando sulfatadas. Todas as análises foram realizadas em temperatura ambiente de $23,5^{\circ} \mathrm{C}$.

Os testes catalíticos de bancada foram executados por meio do processo de esterificação do óleo de algodão via rota etílica com a finalidade de avaliar o desempenho catalítico, antes e pós sulfatação. A Fig. 7 ilustra os resultados alcançados mediante a utilização das amostras 
Tabela $\mathrm{V}$ - pHs das mostras de $\mathrm{ZrO}_{2}$ sintetizado, comercial e sulfatadas a $23,5^{\circ} \mathrm{C}$.

[Table $\mathrm{V}$-pHs of synthesized, commercial and sulfated $\mathrm{ZrO}_{2}$ samples at $23.5^{\circ} \mathrm{C}$.]

\begin{tabular}{cc}
\hline Amostra & $\mathrm{pH}$ \\
\hline $\mathrm{ZrO}_{2}$ sintetizada & 5,12 \\
$\mathrm{ZrO}_{2}$ comercial & 4,92 \\
$\mathrm{SO}_{4}{ }^{2-} / \mathrm{ZrO}_{2}$ sintetizada & 3,21 \\
$\mathrm{SO}_{4}{ }^{2-} / \mathrm{ZrO}_{2}$ comercial & 2,65 \\
\hline
\end{tabular}

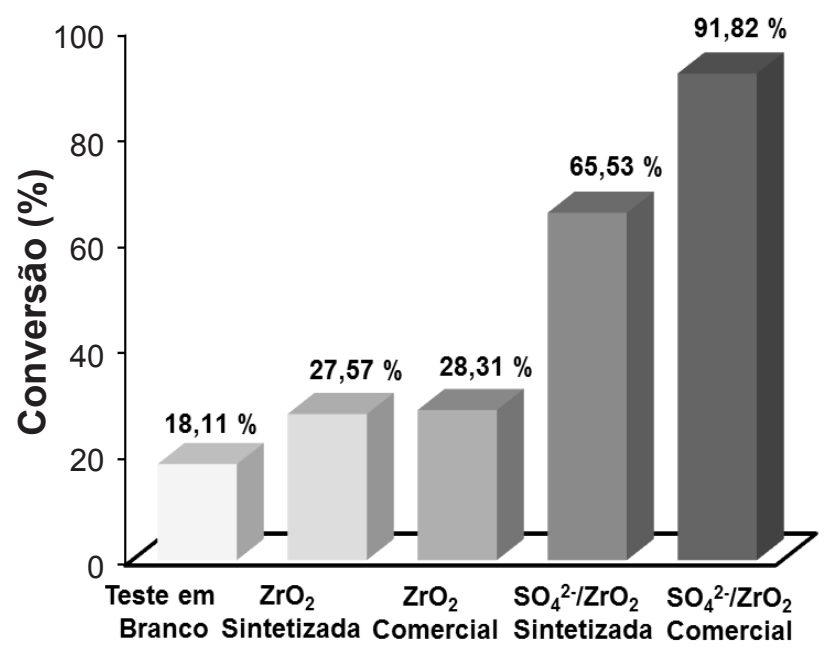

Figura 7: Médias de conversões em triplicata do éster etílico alcançadas com o uso das amostras de $\mathrm{ZrO}_{2}$ (sem e com sulfatação) como catalisadores.

[Figure 7: Averages of conversion in triplicate of the ethyl ester achieved with the use of $\mathrm{ZrO}_{2}$ samples (with and without sulfation) as catalysts.]

estudadas como catalisadores na reação de esterificação com o óleo de algodão. Pôde-se observar que o teste em branco, sem a presença de catalisador, apresentou um teor de conversão em torno de $18 \%$ de ésteres, o que foi relacionado à reação do ácido carboxílico (contendo ácido oleico) com o álcool etílico durante a reação de esterificação, que mesmo sem a presença de um catalisador acarretou na conversão do ácido oleico em éster etílico. Ficou evidente que o $\mathrm{ZrO}_{2}$ sintetizado, que possuiu maior área superficial e menor tamanho de partícula em relação ao $\mathrm{ZrO}_{2}$ comercial (Tabela III), apresentou um nível de conversão muito próximo ao do $\mathrm{ZrO}_{2}$ comercial (27\% contra $28 \%$ ). Isso permitiu confirmar que a diferença de $49,5 \%$ na área de superfície e o tipo de fases presentes nas amostras de zircônia sintetizada e comercial não foi preponderante. As zircônias apresentaram elevação na conversão de ésteres, quando comparado com o valor de conversão obtido para o teste em branco. As zircônias sulfatadas $\left(\mathrm{SO}_{4}{ }^{2-} / \mathrm{ZrO}_{2}\right.$ sintetizado e comercial), segundo método relacionado na literatura [24], apresentaram desempenho bastante favorável, atingindo percentuais nas conversões de ésteres de $65,5 \%$ para o $\mathrm{SO}_{4}^{2-} / \mathrm{ZrO}_{2}$ sin- tetizado com $\mathrm{pH}$ de 3,21 e $91,8 \%$ no $\mathrm{SO}_{4}^{2-} / \mathrm{ZrO}_{2}$ comercial com $\mathrm{pH}$ de 2,65. Os teores de ésteres mais elevados das amostras sulfatadas foram relacionados ao aumento da acidez e ao provável surgimento da fase tetragonal, logo após o processo de impregnação do íon $\mathrm{SO}_{3}$ na superfície das amostras. Essa constatação de a fase tetragonal favorecer uma maior acidez também foi reportada na literatura [36], sendo que o aumento da acidez do $\mathrm{ZrO}_{2}$ sulfatado pode estar relacionado a dois fatores: formação da fase tetragonal e aumento da acidez de Lewis do $\mathrm{ZrO}_{2}$ exercido pelo ânion sulfato durante a calcinação do $\mathrm{SO}_{4}^{2-/ Z \mathrm{ZO}_{2}}$.

\section{CONCLUSÕES}

O método de síntese da reação de combustão mostrouse eficaz, visto que foi possível obter $\mathrm{ZrO}_{2}$ sintetizado por um processo rápido e econômico, usando a ureia como combustível e recipiente com capacidade de produção de $15 \mathrm{~g} /$ batelada do produto. As amostras de $\mathrm{ZrO}_{2}$ comercial e sintetizada apresentaram características morfológicas estruturais diferenciadas, ou seja, a amostra sintetizada apresentou as fases monoclínica/ortorrômbica e o $\mathrm{ZrO}_{2}$ comercial exibiu apenas a fase monoclínica. Após o processo de sulfatação, ocorreu o surgimento da fase tetragonal nas duas amostras e variação do tamanho médio dos diâmetros de partículas, o que pode estar relacionado ao aparecimento dessa nova fase e a impregnação do íon sulfato na superfície das amostras sulfatadas. O processo de sulfatação se mostrou eficaz, pois favoreceu maior acidez das amostras, possibilitando valores de conversão maiores em relação às zircônias não sulfatadas. $\mathrm{O}^{\mathrm{SO}_{4}{ }^{2-} / \mathrm{ZrO}_{2}}$ sintetizado com pH de 3,21 apresentou conversão de 65,5\% de éster etílico, $57,9 \%$ maior que a amostra sintetizada não sulfatada. Já a amostra $\mathrm{SO}_{4}^{2-} / \mathrm{ZrO}_{2}$ comercial com $\mathrm{pH}$ de 2,65 revelou uma conversão de éster etílico de 91,8\%, $67,2 \%$ maior do que a amostra comercial não sulfatada. Ambas as amostras tiveram resultados promissores, mas $\mathrm{o} \mathrm{ZrO}_{2}$ comercial foi mais favorável devido à sua maior acidez ( $\mathrm{pH} 2,65)$. Entretanto, ambas as amostras de $\mathrm{ZrO}_{2}$ foram promissoras para serem usadas como catalizadores na esterificação para a produção de biodiesel.

\section{AGRADECIMENTOS}

Os autores são gratos ao Inct-INAMI, CNPq e PNPD 2011/CAPES pelo apoio financeiro.

\section{REFERÊNCIAS}

[1] F.N. Silva, J. Dantas, R.B.L. Cunha, E.M.J.A. Pallone, A.C.F.M. Costa, Rev. Eletr. Mater. Proces. 8, 1 (2013) 51-54.

[2] H. Akhiani, A. Hunt, X. Cui, A. Moewes, J. Szpunar, J. Alloys Compd. 622 (2015) 463-470.

[3] B. Zhu, C. M. Liu, M.B. Livia, X.R. Chen, J. Zhu, F.J. Guang, Phys. B: Condens. Matter. 406 (2011) 3508-3513.

[4] F.N. Silva, J. Dantas, A.S. Silva, E.M.J.A. Pallone, A.C.F.M. Costa, Mater. Sci. Forum 775-776 (2014) 189-194. 
[5] J. Chevalier, L. Gremillard, J. Am. Ceram. Soc. 92, 9 (2009) 1901-1920.

[6] F. Heshmatpour, R.B. Aghakhanpour, Powder Technol. 205 (2011) 193-200.

[7] D. Fang, S. Liu, Z. Luo, C. Xiong, W. Xu, Appl. Surf. Sci. 258 (2012) 6217-6223.

[8] J.Y. Thompson, B.R. Stoner, J.R. Piascik, R. Smith, Dent. Mater. 27 (2011) 71-82.

[9] Y.T. Liu, T.M. Lee, T.S. Lui, Colloids Surf. B 106 (2013) 37-45.

[10] J. Zhang, S. Chen, R. Yang, Y. Yan, Fuel 89, 10 (2010) 2939-2944.

[11] V.G. Deshmane, Y.G. Adewuri, Microporous Mesoporous Mater. 148 (2012) 88-100.

[12] R. Añez, A. Sierraalta, G. Martorell, P. Sautet, Surf. Sci. $\mathbf{6 0 3}$ (2009) 2526-2531.

[13] I.J. Morales, M.A.R. Tejero, P.B. García, J.S. González, Fuel Process. Technol. 97 (2012) 65-70.

[14] C. Khatri, M.K. Mishra, A. Rani, Fuel Process. Technol. 91 (2010) 1288-1295.

[15] E.C. Grzebielucka, A.S.A. Chinelatto, S.M. Tebcherani, A.L. Chinellatto, Ceram. Int. 36 (2010) 1737-1742.

[16] E.M. Nicholas, N. Kondamudi, L.M. Petkovic, D.M. Ginosar, Appl. Catal. A: General 429-430 (2012) 59-66.

[17] J. Dantas, J.R.D. Santos, R.B. L. Cunha, R.H.G.A. Kiminami, A.C.F.M. Costa, Mater. Res. 16 (2013) 625-627.

[18] K.R.O. Pereira, A.U.A. Júnior, M.W.N.C. Carvalho, A.S. Silva, Quím.: Ciên., Tecnol. Soc. 4 (2015) 56-68.

[19] L.K.Noda, R.M.Almeida, L.F.D.Probst, N.S. Gonçalves, J. Mol. Catal. A: Chem. 225 (2005) 39-46.

[20] S.R. Jain, K.C. Adiga, P. Verneker, Combust. Flame 40 (1981) 71-79.

[21] Y. Sun, S. Ma, Y. Du, L. Yuan, S. Wang, J. Yang, F. Deng, F.S. Xiao, J. Phys. Chem. B 109 (2005) 2567-2572.

[22] M. Sekar, A. Halliyal, J. Am. Ceram. Soc. 81, 2 (1998) 380-388.

[23] J.S. Reed, Principles of ceramics processing, John Wiley Sons, New York (1996).

[24] K.H. Chung, B.G. Park, J. Ind. Eng. Chem. 15 (2009)
388-392.

[25] M.P. Trubelja, D. Petter, J.J. Helble, J. Mater. Sci. 45 (2010) 4480-4489.

[26] Y. Lião, X. Huang, X. Lião, B. Shi, J. Mol. Catal. A: Chem. 347 (2011) 46-51.

[27] G. Trolliard, R. Benmechta, D. Mercurio, Acta Mater. 55 (2007) 6011-6018.

[28] K.M. Rahulan, G. Vinitha, L.D. Stephen, C.C. Kanakam, Ceram. Int. 39 (2013) 5281-5286.

[29] D.E. Baciu, J. Simitzis, D. Giannakopoulos, Dig. J. Nanomater. Bios. 7, 4 (2012) 1779-1786.

[30] G. Singh, K.L. Singh, Int. J. Sci. Emerg. Technol. Latest Trends 3, 1 (2012) 1-8.

[31] A. Hardy, S.V. Elshocht, Adelmannc, T. Conard, A. Franquet, O. Doubért, I. Haeldermans, J.D. Haen, S. De Gendt, M. Gaymax, M. Heyns, M.D'. Olieslaegerl, M.K. Van Bael, J. Mullens, Thin Solid Films 516 (2008) 8343-8351.

[32] H. Mohebbi, T.Ebadzadeh, F.A. Hesari, J. Power Sources 178 (2008) 64-68.

[33] S. Kumar, C.V. Srivastava, R.P. Badoni, Fuel Process. Technol. 93 (2012) 18-25.

[34] F. Heshmatpour, R.B. Aghakhanpour, Adv. Powder Technol. 23 (2012) 80-87.

[35] A. Patel, V. Brahmkhatri, N. Singh, Renew. Energy 51 (2013) 227-233.

[36] A.J.J. Koekkoek, J.A.R. van Veen, P.B. Gerrtisen, P. Giltay, P.C.M.M. Magusin, E.J.M. Hensen, Microporous Mesoporous Mater. 151 (2012) 34-43.

[37] F. Rouquerol, J. Rouquerol, K. Sing, Adsorption by powders and porous solids, Academic Press, San Diego (1999) 191.

[38] P.S. Andreão, R.A. Giacominii, A.M. Stumbo, W.R. Waldman, B.R. Filho, Quím. Nova 33, 1 (2010) 212-215.

[39] Int. Union Pure Appl. Cherm., Handbook 2 (1976) 57.

[40] Y. Chang, S. Dong, H. Wang, K. Du, Q. Zhu, P. Luo, Mater. Res. Bull. 47 (2012) 527-531.

[41] S. Gao, X. Chen, H. Wang, J. Mo, Z. Wu, Y. Liu, X. Wen, J. Colloid Sci. 395 (2013) 515-521.

(Rec. 15/03/2016, Rev. 28/06/2016, 11/11/2016, Ac. 08/02/2017) 